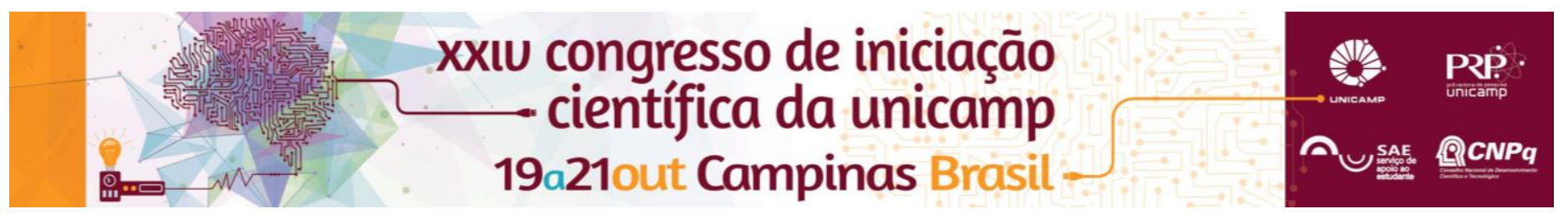

\title{
Desenvolvimento de um Novo Ciclo de Condução em Condições Reais de Tráfego Urbano
}

\author{
André Oliveira*, Elvis Bertoti, Jony J. Eckert, Ludmila C. de A. e Silva.
}

\section{Resumo}

Esse trabalho visa a elaboração de um novo ciclo de condução desenvolvido na cidade de Campinas tendo em vista o amplo emprego desses ciclos em diversas análises e simulações e a deficiência do ciclo padrão brasileiro ao retratar o perfil do tráfego encontrado em áreas urbanas. Logo, o resultado é um ciclo que representa a operação de um veiculo no cenário real de tráfego urbano podendo ser empregado em estudos sobre frenagem regenerativa e outros tópicos.

\section{Palavras-chave:}

Ciclo de Condução, Tráfego Urbano, Condições Reais.

\section{Introdução}

Um ciclo de condução é um perfil padronizado de velocidade por tempo que visa reproduzir um modelo de direção em determinado ambiente. É amplamente utilizado na regulação de emissões de poluentes e no monitoramento do consumo de combustível de veículos [1] justamente por possibilitar a realização de ensaios dentro de condições reprodutíveis.

No Brasil, o ciclo urbano NBR 6601 é usualmente empregado para avaliações de emissão e outras análises. Porém, quando comparado a outros ciclos, como o americano NYCC e o japonês JC-08, percebe-se que o ciclo NBR 6601 apresenta algumas deficiências ao tentar refletir o perfil de tráfego urbano, distinguido pela baixa velocidade média e longos períodos de inatividade como constata-se na Tabela 1.

Desse modo, esse trabalho visa desenvolver um novo ciclo urbano que reproduza mais propriamente o padrão de tráfego encontrado nas grandes cidades sincronizado ao perfil altimétrico do trajeto correspondente, o que também não é incluído no ciclo NBR 6601.

Tabela 1. Comparação de ciclos urbanos [2].

\begin{tabular}{|c|c|c|c|}
\hline & $\begin{array}{c}\text { Velocidade } \\
\text { Média }(\mathrm{km} / \mathrm{h})\end{array}$ & $\begin{array}{c}\% \text { de tempo } \\
\text { inativo }\end{array}$ & $\begin{array}{c}\% \text { de tempo em } \\
\text { frenagem }\end{array}$ \\
\hline NYCC & 11,5 & $31,10 \%$ & $21,57 \%$ \\
\hline JC-08 & 24,4 & $28,7 \%$ & $33,6 \%$ \\
\hline NBR 6601 & 31,6 & $13,81 \%$ & $19,8 \%$ \\
\hline
\end{tabular}

\section{Resultados e Discussão}

Para a elaboração do novo ciclo foi escolhida a cidade de Campinas no horário de pico noturno, das 17-19 horas. Campinas sofreu um aumento de $98,3 \%$ de sua frota automotiva entre os anos 2000 e 2014, chegando à marca de 881.235 veículos. Sendo assim, o fluxo viário da cidade, principalmente no período escolhido, é bem representativo ante outras cidades metropolitanas.

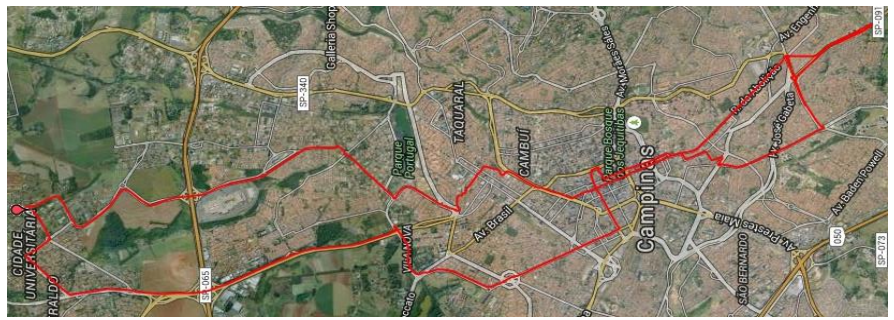

Figura 1. Trajeto percorrido para levantamento do ciclo. DOI: 10.19146/pibic-2016-50731

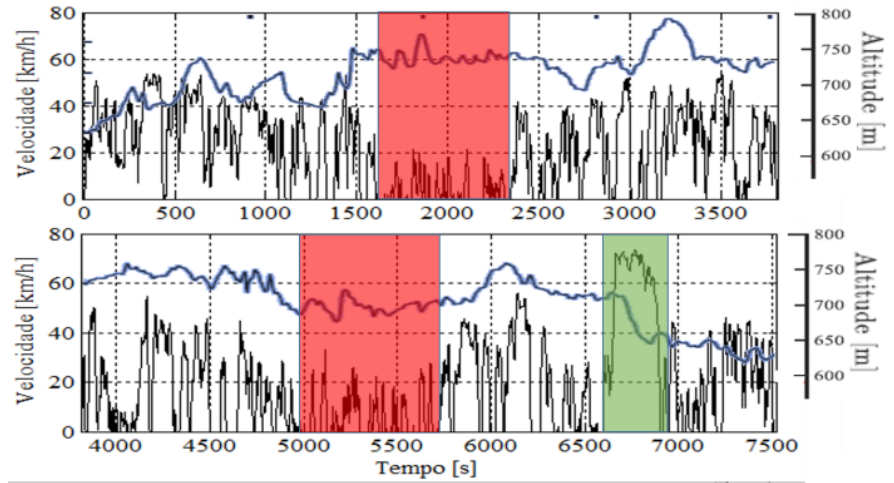

Figura 2. Velocidade (preto) e altitude (azul) do ciclo.

Deste modo foi percorrido o trajeto por vias altamente movimentadas, saindo da Universidade Estadual de Campinas, passando pelo centro da cidade e retornando para a Universidade, como pode ser visto na Figura 1. A Figura 2 retrata o perfil de velocidade associado à elevação, registrado com o auxílio de um equipamento de GPS que permite exportação dos dados da rota.

Nota-se que o trajeto apresenta paradas frequentes e dois momentos de engarrafamento (vermelho), além de um estágio de auto-estrada (verde). Ao final, o ciclo exibiu uma velocidade média de $20,2 \mathrm{~km} / \mathrm{h}$, além de $23 \%$ do tempo em inatividade e $25 \%$ em regime de frenagem.

\section{Conclusões}

O ciclo urbano levantado apresentou um gradiente de aceleração pertinente para simulações e estudos sobre frenagem regenerativa. $O$ ciclo será útil para o estudo do comportamento dinâmico em aclives e declives, também. Finalmente, os resultados do ciclo foram coerentes com as características de diferentes outros ciclos urbanos.

\section{Agradecimentos}

À Fundação de Amparo à Pesquisa do Estado de São Paulo (FAPESP) através do processo no 2015/20319-7, pelo apoio à pesquisa e aos colegas e professores do Laboratório de Sistemas Integrados da FEM/Unicamp.

\footnotetext{
${ }^{1}$ MONTAZERI-GH, M.; NAGHIZADEH, M. Development of car drive cycle for simulation of emissions and fuel economy. In: Proceedings of 15th European simulation symposium. 2003.

2 BARLOW, Tim J, S Latham, IS McCrae, and PG Boulter. 2009. A reference book of driving cycles for use in the measurement of road vehicle emissions.
} XXIV Congresso de Iniciação Científica da UNICAMP 